\title{
Effect of dietary concentrate to forage ratio on growth performance, rumen fermentation and bacterial diversity of Tibetan sheep under barn feeding on Qinghai-Tibetan plateau
}

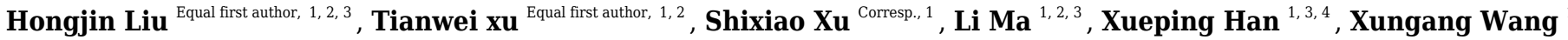 \\ ${ }^{2,3}$, Xiaoling Zhang ${ }^{1,2,3}$, Linyong Hu ${ }^{1,2}$, Na Zhao ${ }^{1,2}$, Yongwei Chen ${ }^{4}, \mathbf{L i}^{\mathbf{P i}^{1}}{ }^{1}$, Xinquan Zhao ${ }^{1,2}$ \\ ${ }^{1}$ Northwest Institue of Plateau Biology, Chinese Academy of Science, Xining, China \\ 2 Key Laboratory of Adaptation and Evolution of Plateau Biota, Chinese Academy of Sciences, Xining, China \\ 3 University of Chinense Academy of Sciences, Beijing, China \\ ${ }^{4}$ Technology Extension Service of Animal Husbandry of Qinghai, Xining, China \\ Corresponding Author: Shixiao Xu \\ Email address: sxxu@nwipb.cas.cn
}

This study aimed to research the effects of different dietary concentrate to forage (C:F) ratio on growth performance, rumen fermentation and bacteria diversity of barn feeding Tibetan sheep. The experiment contains fiver treatments (HS1, HS2 HS3, HS4 and HS5; $n=8$, respectively) based on dietary C: $F$ ratios $0: 100,15: 85,30: 70,45: 55$, and 60:40, respectively. The ruminal bacterial community structure was investigated through highthroughput sequencing of 16S rRNA genes in V4 hypervariable region. The results showed that increasing dietary concentrate feed level from $0 \%$ to $60 \%$ exerted a positive effect on DMI, BW gain, gain rate and feed conversation ratio $\left(F_{C R}\right)$ in Tibetan sheep. The increases dietary concentrate feed level elevated $\mathrm{NH}_{3}-\mathrm{N}$, propionate and valerate concentrations, whereas, reduced molar ratio of acetate to propionate $(A / P$ ratio $)(P<0.05)$. For rumen bacterial diversity, increases in dietary concentrate content contributed to lower alpha diversity indexes including Shannon wiener, Chaol and observed species, meanwhile, significantly increased the abundances of the phylum Bacteroidetes and the genus Prevotella_1 $(\mathrm{P}<0.05)$. In conclusion, increases dietary concentrate content improved the growth performance and Tibetan sheep fed diets of $45 \%$ concentrate obtained a better performance; the inclusion of concentrate in feed changed rumen fermentation from acetate fermentation to propionate fermentation, and improved the energy utilization efficiency of Tibetan sheep; the increased in concentrate content significantly reduced rumen bacteria diversity and changed the abundance of some core bacteria. 
1 Effect of dietary concentrate to forage ratio on growth performance, rumen fermentation

2 and bacterial diversity of Tibetan sheep under barn feeding on Qinghai-Tibetan plateau

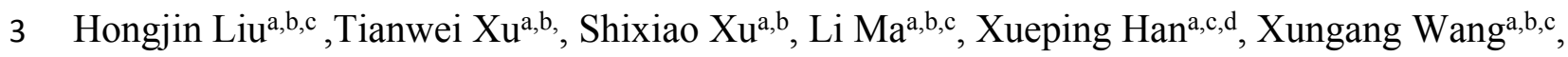

4 Xiaoling Zhang ${ }^{\mathrm{a}, \mathrm{b}, \mathrm{c}}$, Linyong $\mathrm{Hu}^{\mathrm{a}, \mathrm{b}}, \mathrm{Na} \mathrm{Zhao}^{\mathrm{a}, \mathrm{b}}$, Yongwei Chen ${ }^{\mathrm{d}}$, $\mathrm{Li} \mathrm{Pi}^{\mathrm{a}}$, Xinquan Zhao ${ }^{\mathrm{a}, \mathrm{b}}$

5

6 a Northwest Institute of Plateau Biology, Chinese Academy of Sciences, Xining, China

7 bey Laboratory of Adaptation and Evolution of Plateau Biota, Chinese Academy of Sciences,

8 Xining, China

$9{ }^{\mathrm{c}}$ University of Chinese Academy of Sciences, Beijing, China

${ }^{\mathrm{d}}$ Technology Extension Service of Animal Husbandry of Qinghai, Xining, China

Hongjin Liu and Tianwei Xu contributed equally to this research.

*Corresponding author: prof. Shixiao Xu, Northwest Plateau Institute of Biology, Chinese 
25

\section{Abstract:}

This study aimed to research the effects of different dietary concentrate to forage $(\mathrm{C}: \mathrm{F})$ ratio on growth performance, rumen fermentation and bacteria diversity of barn feeding Tibetan sheep. The experiment contains fiver treatments (HS1, HS2 HS3, HS4 and HS5; n=8, respectively) based on dietary $\mathrm{C}$ : F ratios $0: 100,15: 85,30: 70,45: 55$, and 60:40, respectively. The ruminal bacterial community structure was investigated through high-throughput sequencing of 16S rRNA genes in V4 hypervariable region. The results showed that increasing dietary concentrate feed level from $0 \%$ to $60 \%$ exerted a positive effect on DMI, BW gain, gain rate and feed conversation ratio $\left(\mathrm{F}_{\mathrm{CR}}\right)$ in Tibetan sheep. The increases dietary concentrate feed level elevated $\mathrm{NH}_{3}-\mathrm{N}$, propionate and valerate concentrations, whereas, reduced molar ratio of acetate to propionate $(\mathrm{A} / \mathrm{P}$ ratio $)(\mathrm{P}<0.05)$. For rumen bacterial diversity, increases in dietary concentrate content contributed to lower alpha diversity indexes including Shannon wiener, Chao1 and observed species, meanwhile, significantly increased the abundances of the phylum Bacteroidetes and the genus Prevotella_1 $(\mathrm{P}<0.05)$. In conclusion, increases dietary concentrate content improved the growth performance and Tibetan sheep fed diets of $45 \%$ concentrate obtained a better performance; the inclusion of concentrate in feed changed rumen fermentation from acetate fermentation to propionate fermentation, and improved the energy utilization efficiency of Tibetan sheep; the increased in concentrate content significantly reduced rumen bacteria diversity and changed the abundance of some core bacteria.

Keywords Rumen bacterial diversity, Tibetan sheep, 16S rRNA, Concentrate-to-forage ratio, Rumen fermentation parameter, Growth performance

Abbreviation key: C:F ratios $=$ dietary concentrate to forage ratio, $\mathrm{HS} 1=\mathrm{C}: \mathrm{F}$ ratio of 0:100, 
$47 \mathrm{HS} 2=\mathrm{C}: \mathrm{F}$ ratio of $15: 85, \mathrm{HS} 3=\mathrm{C}: \mathrm{F}$ ratio of $30: 70, \mathrm{HS} 4=\mathrm{C}: \mathrm{F}$ ratio of $45: 55, \mathrm{HS} 5=\mathrm{C}: \mathrm{F}$ ratio of

$4860: 40, \mathrm{DMI}=$ dry matter intake, $\mathrm{ADG}=$ average daily $\mathrm{BW}$ gain, $\mathrm{F}_{\mathrm{CR}}=$ feed conversation ratio.

\section{Introduction}

Tibetan sheep (Ovis aries) live exclusively on the Qinghai Tibetan Plateau (QTP) with a altitude greater than 3,000 (An et al. 2005), they have adapted well to extremely harsh environment and ingested grasses as their sole source of nutrition (Sasaki 1994; Wiener et al. 2003). Under traditional management, Tibetan sheep mainly grazed on natural pasture without concentrate supplementation, and always suffered seasonal live-weight variations and viciously cycled in "alive in summer, strong in autumn, thin in winter, tired in spring", due to seasonal fluctuations in natural pasture supply and the contradiction between herbage supply and livestock's requirement on the alpine pasture (Dong et al. 2006; Xue et al. 2005; Xu et al. 2017). During growing season (June to Oct.), natural pasture can provide enough herbage for livestock, the local people only drive livestock to alpine pasture for grazing. During non-growing season (Nov to May) and vegetation green-up periods, grazing livestock shared low performance mainly attributed to the decrement in herbage supply (both in quantity and quality). In addition, irrational grazing during this period destroyed regular growth of alpine plants and function recovery of alpine pasture. Previous studies have confirmed that spring short term rest-grazing is an effective measure for the functional recovery of alpine meadows (Li et al. 2014; Li et al.2017; Ma et al.2017), the local government encourages pastoralists to feed their livestock in warm shed during spring grazing break. However, few studies concerning growth performance of barn feeding Tibetan sheep during late non-growing and vegetation green-up periods were conducted, but which was quiet important for providing pastoralists guidance in livestock breeding.

$$
\text { The rumen microorganisms play an important role in the digestion of proteins, }
$$


carbohydrates, starch, sugars and fats, which provides energy and proteins to the host by producing volatile fatty acids and bacterial proteins through anaerobic fermentation (Ceconi et al. 2015; Jiang et al. 2015) and finally affects ruminants performance. The rumen microorganism can be affected by many factors, such as diet, hosts and geographic region (Clark. 1975; Lee et al. 2012). The dietary nutrition level is a major factor affecting rumen microbial diversity, healthy status and production capacity of ruminants (Clark. 1975). The effect of diet on the structure of rumen microbial communities has been widely investigated in Yak, Tan sheep, Holstein dairy cows, Mehshana buffalo and goats (Pitta et al. 2014; Jiao et al. 2015; Pitta et al. 2016; Wang et al. 2016; Xue et al. 2016). However, as the dominant ruminant and living foundation for local herdsman, the studies of Tibetan sheep have only focused on the growth performance, slaughter performance and economic benefit under different dietary supplementation (Baruah et al. 2012; Chen et al. 2015c; Dodd et al. 2011; Feng et al. 2013; Lee et al. 2012; Xu et al. 2017), but few comprehensive studies focused on the growth performance, rumen fermentation and rumen microbial communities of Tibetan sheep.

Therefore, this study aimed to investigate the growth performance, rumen fermentation and rumen bacterial diversity of Tibetan sheep under different dietary concentrate-to-forage ratios during late non-growing and green-up periods. We hypothesized that different C: F ratios could affect growth performance, rumen fermentation and rumen bacterial diversity in Tibetan sheep. These results will be of great importance for providing guidance for local herdsmen in Tibetan sheep breeding and for future research on rumen microbial metabolism in Tibetan sheep.

Materials and Methods

Animals and Experimental Design 
92

93

94

This study was conducted at Haibei Demonstration Zone of Plateau Modern Ecological Animal Husandry Scientific and Technology in Haibei Prefecture, Qinghai Province, China (36 $54^{\prime}$ N, $100^{\circ} 56^{\prime}$ E), from April 2016 to July 2016. All animal care procedures were consistent with the guidelines from the Institution of Animal Care and the Ethics Committee of the Northwest Institute of Plateau Biology, Chinese Academy of Sciences (NWIPB20160302). The processing of the samples after collection was performed strictly in accordance with the guidelines of NWIPB.

A total of 40 female yearling Tibetan sheep with familiar body conditions $(21.39 \pm 1.18 \mathrm{~kg}$ BW, and not under current antibiotic treatment) were randomly divided into five treatments ( 8 in each) under different C:F ratios (on dry matter basis):HS1(0:100), HS2 (15:85), HS3 (30:70), HS4 (45:55) and HS5 (60:40), respectively. All sheep were allocated into 5 pens within a warm shed. The concentrate and oat hay were manually mixed and fed (dry matter) based on 3.5\% BW of Tibetan sheep. Before study, all the animals were fed the experimental diet for a 15-day adaptation phase. During formal 80 day experiment, the experimental animals were separately fed twice dairy, at 8:00 am and 5:00 pm. The diets, salt brick and clean water were available throughout the entire experiment. The ingredients and nutrient compositions of the animal diet are shown in Table 1 and Table S1. The concentrate feed used in this study was produced by Menyuan Yongxing Ecological Agricultural Development Co., Ltd., and oat hay are harvested, bundled and stored in the year 2015.

\section{Measurement and sampling}

The diets and oats in each treatment were weighed and recorded daily to estimate individual dry matter intake (DMI). Diet samples of approximately $500 \mathrm{~g}$ from each treatment were collected, dried at $60^{\circ} \mathrm{C}$, ground through a 1-mm sieve and stored in a vacuum dryer for 
115 nutritional analysis. To measure animal growth performance, Tibetan sheep were weighed before

116 feeding using an electronic balance at the beginning and end of formal experiment. We selected

117 four Tibetan sheep from each treatment group for rumen fluid sampling. Specifically, on $80^{\text {th }}$

118 day, rumen content samples were obtained 3-4 $\mathrm{h}$ after the morning feeding using a stomach tube

119 attached to an electric pump, which has been confirmed to yield similar results for rumen

120 microorganisms and fermentation parameters as sampling using a rumen cannula (Ramos-

121 Morales et al. 2014). The rumen contents were filtered through four layers of sterilized gauze.

122 Approximately $67 \mathrm{~mL}$ of liquid was obtained from the rumen of each Tibetan sheep. The rumen

123 fluid was separated into three samples, one (approximately $2 \mathrm{~mL}$ ) was transferred into sterilized

124 freezing tubes and stored in liquid nitrogen for DNA extraction; the second sample

125 (approximately $15 \mathrm{~mL}$ ) was immediately used to measure the $\mathrm{pH}$; and the third sample

126 (approximately $50 \mathrm{~mL}$ ) was used for the assessment of rumen fermentation parameters, including

127 ammonia nitrogen $\left(\mathrm{NH}_{3}-\mathrm{N}\right)$ and rumen volatile fatty acids (VFAs).

\section{Chemical analysis and calculation}

The feed samples were fried in an oven at $135^{\circ} \mathrm{C}$ for $3 \mathrm{~h}$ to obtain the DM (AOAC, 1990;

130

131

132

133

134

135

136

137
Method No. 930.15). The total N was detected using Kjeldahl method; the crude protein content was calculated as $6.25 \times \mathrm{N}$ (Method No. 984.13); the ether extract (EE) was measured using the Soxhlet system (Method No. 954.02); the acid detergent fiber (ADF) and neutral detergent fiber (NDF) of diet were analysed using method described by Soest et al. (1991); and the starch was measured according to PRC national standard (GB 5009.9-2016).

The body weight gain (BW gain), gain rate, average daily BW gain (ADG) and feed conversion ratio $\left(\mathrm{F}_{\mathrm{CR}}\right)$ were calculated according to the following equations:

$$
\mathrm{BW}_{\text {gain }}(\mathrm{kg})=\mathrm{BW}_{\mathrm{f}}-\mathrm{BW}_{\mathrm{i}}
$$

PeerJ reviewing PDF | (2019:01:34522:2:0:NEW 9 Jul 2019) 
138

139

140

141

142

143

144

145

146

147

148

149

150

151

152

153

154

155

156

157

158

159

160

161

$$
\begin{gathered}
\text { Gain rate }(\%)=100 \times\left(\mathrm{BW}_{\mathrm{f}}-\mathrm{BW}_{\mathrm{i}}\right) / \mathrm{BW}_{\mathrm{i}} \\
\mathrm{ADG}(\mathrm{g} / \mathrm{d})=1000 \times\left(\mathrm{BW}_{\mathrm{f}}-\mathrm{BW}_{\mathrm{i}}\right) / \mathrm{t} \\
\mathrm{F}_{\mathrm{CR}}=\mathrm{DM}_{\text {consume }} /\left(\mathrm{BW}_{\mathrm{f}}-\mathrm{BW}_{\mathrm{i}}\right)
\end{gathered}
$$

where $\mathrm{BW}_{\mathrm{f}}$ and $\mathrm{BW}_{\mathrm{i}}$ are the final and initial body weights $(\mathrm{kg})$, respectively, $\mathrm{t}$ is the

experimental time (d), and $\mathrm{DM}_{\text {consume }}$ is the total feed consumed during the experiment $(\mathrm{kg} \mathrm{DM})$.

The ruminal fluid $\mathrm{pH}$ was measured using a portable $\mathrm{pH}$ meter (PHSJ-3F; Precision Instruments

Company, Shang Hai, China). For VFAs measurements, the rumen fluid was centrifuged at $12,000 \mathrm{~g}$ for $15 \mathrm{~min}$, and the VFAs in the supernatant were analysed using a gas chromatograph Agilent 7890A (Agilent Technologies Inc., Santa Clara, CA, USA) equipped with a polar capillary column (DB-WAX, $30 \mathrm{~m} \times 0.25 \mathrm{~mm} \times 0.25 \mu \mathrm{m}$ ) and a flame ionization detector (FID, temperature set at $250^{\circ} \mathrm{C}$ ). The temperature-programmed conditions were as follows: the temperature was maintained at $60^{\circ} \mathrm{C}$ for 2 minutes, increased to $180{ }^{\circ} \mathrm{C}$ at rate of $10^{\circ} \mathrm{C} / \mathrm{min}$, and increased to $250{ }^{\circ} \mathrm{C}$ at rate of $20^{\circ} \mathrm{C} / \mathrm{min}$; the shunt ratio was $20: 1$; the flow rate was 1 $\mathrm{mL} / \mathrm{min}$; and the inlet temperature was $200^{\circ} \mathrm{C}$. The $\mathrm{NH}_{3}-\mathrm{N}$ content in the supernatant was quantified using a continuous flow analyser (SEAL Auto Analyser 3, Germany) described by Rhine et al. (1998).

\section{DNA extraction and PCR amplification}

Genomic DNA was directly extracted from $0.2 \mathrm{~g}$ of each semisolid-state sample using cetyl trimethylammonium bromide (CTAB) method (Porebski et al. 1997). The DNA quality was assessed via 2\% agarose gel elcectrophoresis, and metagenomic DNA concentratios were determined with a NanoDrop 2000 (Thermo, Mass, USA). The DNA was then diluted to $1 \mathrm{ng} / \mu \mathrm{L}$ using sterile water and stored at $-4^{\circ} \mathrm{C}$ for PCR amplification.

For PCR amplification, the V4 hypervariable region of the bacterial 16S rRNA gene was amplified using the universal primers 515F (5'-GTGCCAGCMGCCGCGGTAA-3') and 806R 
162 (5'- GGACTACHVGGGTWTCTAAT-3') with unique barcodes. PCRs were performed in $25 \mu \mathrm{L}$

163 reactions consisting of $12.5 \mu \mathrm{L}$ Phusion ${ }^{\circledR}$ High-Fidelity PCR Master Mix (New England

164 Biolabs), $1 \mu \mathrm{L}$ of forward and reverse primers, $1 \mu \mathrm{L}$ of template DNA and $9.5 \mu \mathrm{L}$ of autoclaved

165 distilled water. The thermal cycling program consisted of initial denaturation at $94^{\circ} \mathrm{C}$ for $3 \mathrm{~min}$,

16630 cycles of denaturation at $94^{\circ} \mathrm{C}$ for $40 \mathrm{~s}$, annealing at $56^{\circ} \mathrm{C}$ for $1 \mathrm{~min}$, and elongation at $72^{\circ} \mathrm{C}$

167 for $1 \mathrm{~min}$ and a final incubation step at $72^{\circ} \mathrm{C}$ for $10 \mathrm{~min}$. For PCR product quantification and

168 qualification, we obtained mixtures of the same volumes of $1 \times$ loading buffer (containing SYBR

169 Green from Shanghai, SanoBio) and the PCR products were exmined ona 2\% agarose gel

170 electrophoresis. Samples with a bright band between 400 and $450 \mathrm{bp}$ were mixed and purified

171 using a Qiagen Gel Extraction Kit (Qiagen, Germany). Sequencing libraries were then generated

172 using a TruSeq ${ }^{\circledR}$ Ultra $^{\mathrm{TM}}$ DNA Library Prep Kit for Illumina (NEB, USA) following the

173 manufacturer's recommendations, and the index codes were then added. The library quality was

174 assessed using a Qubit ${ }^{\circledR} 2.0$ fluorometer (Thermo Scientific) and an Agilent Bio analyzer

175 system. The library was sequenced on an Illumina HiSeq PE250 platform (Novogene, Beijing,

176 China).

177 Analysis of sequencing data

178 The paired-end reads were assigned to samples based on their unique barcodes, and the

179 barcodes and primer sequences were then trimmed. The raw reads were filtered according to the

180 following rules: Removing reads containing more than $10 \%$ of unknown nucleotides $(\mathrm{N})$;

181 removing reads containing less than $80 \%$ of bases with quality (Q-value) $>20$. The FLASH

182 (version 1.2.7) was then used to merge paired-ends reads as raw tags with a minimum overlap of

$18310 \mathrm{bp}$ and mismatch error rates of 2\% (Magoc \& Salzberg 2011). The noisy sequences of raw

184 tags were filtered by QIIME (version 1.9.1) pipeline to obtain the high-quality clean tags

PeerJ reviewing PDF | (2019:01:34522:2:0:NEW 9 Jul 2019) 
185 (Caporaso et al. 2010). The reads were then compared with a Gold database using the UCHIME 186 algorithm to detect and remove the chimaera sequences (Edgaret et al. 2011). All the sequences 187 were analysed using Uparse software (version 7.0.1001), and sequences with greater than or 188 equal 97\% similarity were assigned to the same operational taxonomic unit (OTU). Taxonomic information for each representative sequence was annotated using the Greengenes database based on the RDP classifier algorithm (version 2.2) (Wang et al. 2007).

191

\section{Statistical analysis}

Alpha and species diversity indexes, including the Shannon-Wiener indexe, Chaol index, Good's coverage and observed species were calculated by Qiime and graphed using Origin (version 8.0). The correlation among growth performance, rumen fermentation parameters and bacteria diversity were analyzed using SPSS (version 17.0), and heat map of correlations were also prepared using Origin. The beta diversity based on weighted UniFrac distance, was visualized through a principal coordinate analysis (PCoA). One-way ANOVA with Tuckey's test was performed to compare the differences in relative abundances among different treatments, and Duncan's multiple comparison test was used to determine the effects of dietary C: F ratios on $\mathrm{BW}$ gain, gain rate, $\mathrm{ADG}, \mathrm{DMI}, \mathrm{DM}$ consume and $\mathrm{F}_{\mathrm{CR}}$ using SPSS (version 17.0). Effects were considered significant at $\mathrm{P}<0.05$. The results are shown as the means \pm SEMs.

\section{Results}

\section{Growth performance of Tibetan sheep}

As shown in Table 2, treatments HS4 and HS5 significantly increased BW gain, gain rate and $\mathrm{ADG}$, whereas reduced $\mathrm{F}_{\mathrm{CR}}$ as compared to treatments $\mathrm{HS} 1$ and $\mathrm{HS} 2(\mathrm{P}<0.05)$. Tibetan sheep fed diet in group HS1 showed the lowest growth performance. No significant difference were detected in BW gain and $\mathrm{F}_{\mathrm{CR}}$ between treatments HS4 and HS5, and the initial BW showed 
208 no notably difference among the five groups $(\mathrm{P}=0.196)$.

209 Rumen fermentation parameters

210

211

212

213

214

215

216

217

218

219

220

221

222

223

224

225

226

227

228

229

As shown in Table 3, the $\mathrm{NH}_{3}-\mathrm{N}$, propionate and valerate concentrations in treatments HS4 and HS5 were significantly higher than that of other three groups $(\mathrm{P}<0.05)$. There was a decreasing trend for total VFA, acetate and isovalerate concentrations, but no significant differences were detected among the groups. The increases in dietary concentrate level significantly decreased A:P ratio $(\mathrm{P}<0.05)$. The ruminal $\mathrm{pH}$ tended to decrease, but no significant difference was detected $(\mathrm{P}>0.05)$, and the average $\mathrm{pH}$ value was approximately 6.61 .

\section{Sequencing and taxonomic composition of the rumen bacterial community}

A total of 1,497,607 PE reads were obtained, and 1,461,673 clean reads from 20 different samples were generated after quality control (Table S2). All the sequences were aligned and clustered into OTUs using a 97\% sequence identity as a cut-off, which yielded a total of 49,216 OTUs (Table S2). Rarefaction curves were generated with a 3\% cut of for comparisons of species and richness as shown in Fig. 1. All the curves of the observed species numbers tended to saturate to a plateau at the minimum sequence number of 60,000 tags. In addition, the HS4 and HS5 groups tended to cluster together with a lower observed species number than the HS1, HS2 and HS3 groups.

The taxonomic analysis detected a total of 41 phyla (Table S3), and the most abundant phyla were Bacteroidetes (52.18\%), Proteobacteria (20.34\%) and Firmicutes $(14.34 \%)$. The top ten phyla, which exhibited the highest relative abundances, were prevalent in all the samples, accounting for nearly 98\% of all sequences (Fig. 2A). The moderate abundant phyla included Fibrobacteres (1.25\%), Cyanobacteria (1.04\%), Acidobacteria (0.96\%), Tenericutes (1.49\%), 
230 Actinobacteria (0.96\%) and Verrucomicrobia (0.47\%). The other known phyla accounted for

$2311.48 \%$, whereas the remaining sequences that were unclassified accounted for $0.26 \%$.

232 At the genus level, we detected 129 distinct genera across all the groups (Table S4), and 10 233 genera whose relative abundances more than $1 \%$ were perceived as the most important bacteria

234 that affecting the rumen environment and digestive system (Fig. 2B). The genus with relatively 235 high across all the samples were Prevotella_l (26.81\%), Succinivibrionaceae_UCG-002

236 (7.11\%), Ruminobacter (6.03\%), Rikenellaceae_RC9_gut_group (4.73\%), Prevotellaceae_UCG237003 (2.65\%). Minor genera, such as Prevotellaceae_UCG-001, Erysipelotrichaceae_UCG-004, 238 Fibrobacter, Christensenellaceae_R-7_group and Ruminococcaceae_NK4A214_group

239

240

241

242

243

244

245

246

247

248

249

250

251 accounted for $1.23 \%, 1.09 \%, 1.01 \%, 1.22$ and $1.09 \%$ of the sequences, respectively. The other known genera accounted for $11.32 \%$ of the sequences, whereas sequences that were unclassified accounted for $34.23 \%$ of the sequences.

\section{Effect of diets with different $C: F$ ratios on the bacterial community}

To determine alpha diversity, we calculated Shannon-Wiener, Chao 1, observed species and Good's coverage indexes, as shown in Fig. 3. The indexes of Shannon-Wiener, Chao 1 and observed species in treatments HS1, HS2 and HS3 were significantly higher than treatments HS4 and HS5 (Fig. 3A, B and C). The Good's coverage among five treatment were greater than 99\% (Fig. 3D). As shown in Fig. 4, the PCoA result showed that the rumen bacterial communities of the five treatments were mainly classified into three clusters (Fig. 4). The HS1 and HS2 treatments clustered very closely together, the HS4 and HS5, and the HS3 treatments formed two clusters. In addition, HS3 treatment were closer to the cluster composed of the HS1 and HS2 treatments, which only represented $7.14 \%$ of the variability obtained with PC2.

PeerJ reviewing PDF | (2019:01:34522:2:0:NEW 9 Jul 2019) 
252

253

254

255

256

257

258

259

260

261

262

263

264

265

266

267

268

269

270

271

272

273

274

The relative abundance of bacterial taxa was used to describe the impact of diets with different $C: F$ ratios on bacterial community. At the phylum level, top 8 phylum (relative abundance $>1 \%$ ) were analyzed in Table S5. The ruminal compositions of the HS1 to HS3 treatments contained a significantly lower relative abundance of Bacteroidetes, whereas higher relative abundances of Proteobacteria, Acidobacteria, and Actinobacteria than those of the HS4 and HS5 treatments $(\mathrm{P}<0.05)$. No significant differences were found in the other phyla $(\mathrm{P}>0.05)$. At the genus level, top 12 genera (relative abundance $>1 \%$ ) were analyzed in Table

S6. Treatments HS4 and HS5 shared a higher relative abundance of Prevotella_1 than the other three treatments $(\mathrm{P}<0.05)$. No significant differences were found in the rest of genera $(\mathrm{p}>0.05)$.

\section{Relationships between rumen bacterial diversity and host growth performance}

As shown in Fig. 5, a significant negative correlation was found between bacterial diversity (including the Shannon-Wiener, Chao1, and observed species indexes) and growth performance (including $\mathrm{BW}$ gain, $\mathrm{ADG}$, and $\mathrm{DMI})$ with increases in the $\mathrm{C}: \mathrm{F}$ ratio $(\mathrm{P}<0.05) . \mathrm{F}_{\mathrm{CR}}$ showed a negative correlation with increases in the DMI, BW gain and ADG and a positive correlation with the Shannon-Wiener, Chao1 and observed species indexes. In addition, growth performance showed significant positive correlations with increases in the dietary $\mathrm{C}: \mathrm{F}$ ratio $(\mathrm{P}<0.05)$.

\section{Relationships between rumen fermentation parameter and microorganisms}

A heat map of the correlations between the top 45 genera (relative abundance $>0.1 \%$ ) and rumen fermentation was constructed (Fig. 6). A total of 360 correlation coefficients were generated, and 33 of these coefficients $(9.17 \%$ of the total correlation coefficients) showed significant correlations $(\mathrm{P}<0.05)$. The fermentation parameters $\mathrm{pH}$, acetate, isovalerate and $\mathrm{A}: \mathrm{P}$ were significantly positively correlated with most genera (e.g., Victivalls, Thalassospira and Sphaerochaeta), whereas valerate and $\mathrm{NH}_{3}$ showed a negative correlation with most genera (e.g., 
275 Victivalls, Ruminococcaceae_UCG_02, and Thalassosphira). Prevotella_1, which was the most

276 abundant genera, was significantly positively $(\mathrm{P}<0.05)$ correlated with $\mathrm{NH}_{3}$, propionate and

277 valerate and negatively correlated with $\mathrm{pH}$. No significant correlation were detected between

278 butyrate and the top 45 genera.

279 Discussion

280 Growth performance of barn-fed Tibetan sheep

281 Previous studies mainly aimed to ensure that Tibetan sheep live through grazing breaks (Ma

282 2008; Xie et al. 2014), and there is little knowledge on the BW gain and feed efficiency of

283 Tibetan sheep fed diets with different C:F ratios during late non-growing and vegetation green-

284 up periods. Our results revealed that increases in dietary concentrate feed levels within a certain

285 range $(0 \%$ to $45 \%)$ exerted a positive effect on the feed intake, $\mathrm{BW}$ gain and $\mathrm{F}_{\mathrm{CR}}$ of Tibetan

286 sheep during spring grazing breaks. This finding can be mainly attributed to the fact that high-

287 concentrate diet contains more digestive energy and nonstructural carbohydrates (Wang 2015),

288 which leads to increased nutrient intake, faster digestion through the digestive tract, and then

289 improved growth performance and higher feed efficiency (Haddad \& Ata 2009; Haddad 2005).

290 Under traditional grazing, Tibetan sheep exhibit low growth performance (ADG $=36 \sim 55$

$291 \mathrm{~g} / \mathrm{d}$ ) during spring, and more seriously, unsustainable grazing during this period decreases the

292 plant species richness and biomass in alpine pasture (Ma 2008). In contrast, shortened rest-

293 grazing increases the standing herbage biomass by 77\% 189\% (Li et al. 2017; Ma et al. 2017).

294 Herein, we confirmed that a diet with diet with a 45\% concentration supplementation

295 significantly improves the performance of Tibetan sheep. Therefore, the use of spring rest-

296 grazing combined with barn feeding could increase livestock performance and promote the

297 functional recovery of alpine pasture.

PeerJ reviewing PDF | (2019:01:34522:2:0:NEW 9 Jul 2019) 
298

299

300

301

302

303

304

305

306

307

308

309

310

311

312

313

314

315

316

317

318

319

320

\section{Effect of different C: F ratios on rumen fermentation parameters}

The $\mathrm{pH}, \mathrm{NH}_{3}-\mathrm{N}$ concentration and VFA molar ratio are the main internal environmental indicators of rumen fermentation. If the rumen $\mathrm{pH}$ was in the range of 6.2 to 7.0 , the ecological environment of rumen microorganisms could be relatively stable, which could ensure normal rumen fermentation (Weng et al. 2013; Zhang et al. 2013). In our study, the ruminal pH ranged from 6.42 to 6.86 , and this finding indicated that the increased proportion of concentrate did not induce acidosis, which is usually defined as a decrease in the rumen $\mathrm{pH}$ to less than the threshold value of 6.0 (Nocek 1997). The ruminant $\mathrm{pH}$ values obtained in the present study are inconsistent with previous studies (Cerrillo et al. 1999; Chen et al. 2015a). The pH value can be affected by many factors, such as higher doses of flour or starches (Lettat et al. 2010; Minuti et al. 2014), the time from concentrate feed supplementation to ruminal liquid collection (Lettat et al. 2010), and the insertion depth of the rumen catheter (Li et al. 2009). In our study, increases in the dietary concentrate level tended to decrease the ruminal $\mathrm{pH}$, but no significant difference was detected $(\mathrm{P}>0.05)$, which could be due to the starch content. The HS1 and HS2 groups had a lower starch content (25.58 and $26.95 \mathrm{mg} / \mathrm{g}$, respectively), which led to a higher $\mathrm{pH}$ value, whereas the HS3, HS4 and HS5 groups had a higher starch content $(32.55,33.72$ and $39.37 \mathrm{mg} / \mathrm{g}$, respectively), which resulted in a relatively lower $\mathrm{pH}$ value. The dietary $\mathrm{C}: \mathrm{F}$ ratios did not significantly affect the total volatile fatty acids, which is in accordance with previous research (Chen et al. 2015a). This result might be due to the ability of the rumen system that can adapt to appropriate dietary $\mathrm{C}: \mathrm{F}$ ratios through the self-adjustment of rumen microorganisms. Ammonium nitrogen which is the final product through the decomposition of protein and nonprotein in feed, and it is also the main nitrogen source for the synthesis of bacterial protein by rumen microorganisms. In our study, high concentrate feed level elevated NH3-N concentration, which is consistent with the 
321 former study (Reddy \& Reddy. 1985; Yang et al. 2001). The high dietary concentrate increased

322 nitrogen content in the rumen, thereby increasing ruminal ammonia nitrogen (Moorby et al.

323 2006). As for individual VFA concentrations in current study, diets with high-concentrate levels

324 slightly reduced acetate concentration, whereas significantly increased propionate proportion,

325 thereby resulting in a significant reduction of A: P ratio. (Andrade \& Schmidely 2006; Polyorach

326 et al. 2014). From the point of view of energy utilization, a decrease in the A:P ratio reflects an

327 improvement in the feed energy utilization efficiency, which also explains the improved growth

328 performance of Tibetan sheep in the high-concentrate groups (HS4 and HS5).

\section{Core bacterial communities in the rumen}

Although rumen microbial community composition varies with diet and host, a 'core

microbiome' is found across a wide geographical range (Herdson et al. 2015). The dominance of

332

333

334

335

336

337

338

339

340

341

342 343

Bacteroidetes or Proteobacteria could be attributable to variations in diet, environment, hosts and farming practices over a wide geographical range (Amato et al. 2013; Henderson et al. 2013). In our study, different dietary concentrate level induced Bacteroidetes $(55.02 \%)$ to become the most abundant phyla, followed by Proteobacteria $(22.10 \%)$, and this microbial distribution of major phyla was similar to that obtained in previous studies on Yaks (Chen et al. 2015b). These results might be related to the functions of rumen bacteria. Members of the phylum Bacteroidetes have a greater ability to degrade protein and carbohydrates than species belonging to Proteobacteria (Huo et al. 2014; Pitta et al. 2014). Our study also found that the relative abundance of Firmicutes was the third largest phylum and was lower than that of Proteobacteria. Similar results were observed in bovines and cattle during the transition from forage to concentrate (Jami et al. 2013). However, Xue et al. (2016) observed that the most abundant phyla in the rumen of natural pasture-grazing Tibetan sheep are Bacteroidetes, 
344 followed by Firmicutes. One possible reason for this difference is that the hosts investigated by 345 Xue et al. (2016) were grazed on natural pasture and that the forage nutrition and types differed 346 from those in our study, and these differences might have resulted in a higher abundance of 347 Firmicutes.Additionally, the phylum Fibrobacteres, with an abundance less than 1.5\%, 348 comprised only a small fraction of the community composition compared with those of other 349 phyla, and these results agree with previous studies (Petri et al. 2013; Wang et al. 2016). In our study, although different $\mathrm{C}: \mathrm{F}$ ratio did not change the core structure of the rumen

351 352

microbiome, the relative abundances of Bacteroidetes and Proteobacteria showed noticeable shifts at phylum level. Tibetan sheep fed high-concentrate diets significantly increased the relative abundance of Bcateroidetes, whereas, reduced the relative abundance of Proteobacteria. Pervious research revealed that Bacteroidetes were the major rumen microorganisms in degrading non-fibrous carbohydrates and contained genes related to the degradation of nonfibrous polysaccharides (Russell \& Diezgonzalez. 1998). In our study, high concentrate feed contained more non-fibrous carbohydrates and polysaccharides, thus, increased the abundance of Bacteroidetes. At the genus level, Prevotella_l was the predominant genus, and the relative abundances of this genus significantly increased with increases in dietary C:F ratio. This finding was consistent with that previously obtained by Stevenson \& Weimer et al. (2007). The high abundance of this genus can perhaps be explained from two points of view. Firstly, it if possible that this bacterial genus has a wide metabolic niche due to genetic relatedness or to the high genetic variability that enable this genus to occupy different ecological niches within the rumen. Secondly, Prevotella_1 strains play an important role in the degradation and utilization of plant noncellulosic polysaccharides, protein, starch and xylans. The increase in the abundance of this genus could be attributed to dietary nutrition changes, such as increased dietary protein and 
367 starch. In addition, Prevotella_l is also considered to be associated with propionic acid

368 production (Strobel 1996), which might also explain the increasing proportion of propionate

369 obtained with increase in the C:F ratio.

\section{Relationship between bacterial diversity and growth performance of Tibetan sheep}

In the past 50 years, humans have drastically altered the diet that ruminants consume. The

372

373

374

375

376

377

378

379

380

381

382

383

384

385

386

387

388

389

use of grain feed increases the productivity of animals and the economic benefit of animal

husbandry. In our study, the diversity and richness was significantly lower in high dietary C:F

ratios treatments than low dietary C: F ratios (HS1, HS2 and HS3). Lin et al. (2015) found that the Shannon diversity index of bacteria were higher in low concentrate diet group than in high concentrate diet group concentrate diet group (Lin et al., 2015). Liu et al. (2015) discovered the diversity of ruminal epithelial bacterial community from goats fed the hay diet were significantly higher than those fed the high-grain diet (Liu et al., 2015). Diet composition may effect on the diversity index of microorganisms. The increase in microbial diversity could be because low dietary concentrate diets provide a greater range of carbohydrate substrates (e.g., cellulose and many heteropolysaccharides) than high dietary concentrate treatments and/ or because microorganisms grow faster in high $\mathrm{pH}$ conditions (Hobson \& Stewart. 2012). The growth performance results indicated that increases in the concentrate feed level from 0 to $45 \%$, exerted a positive effect on the feed intake, $\mathrm{BW}$ gain, gain rate and $\mathrm{F}_{\mathrm{CR}}$ in Tibetan sheep. Therefore, based on our findings, we can conclude that improved growth performance is not linked to a higher diversity of rumen microorganisms. It is well known that a decrease in the bacterial diversity can induce the evolution of a certain bacterial group and thereby its dominance in the community. Thus, in our study, a decrease in bacteria diversity is associated with a higher dominance index (phyla Bacteroidetes and genera Prevotella_1), which ensured that the host 
390

391

392

394

395

396

397

398

399

400

401

402

403

404

405

406

407

408

409

410

411

412

could receive more nutrition and ultimately exhibits an improved growth performance. In

addition, in our study, increases in the dietary $C: F$ ratio from $0: 100$ to $30: 70$ were associated with

increases in both the rumen bacterial diversity and the host growth performance, whereas, dietary

C:F ratios of 45:55 and 60:40 could only promote growth performance of Tibetan sheep.

Briesacher et al. (1992) observed that the digestive of the rumen is influenced by the number of

bacterial species and the total abundance of bacteria. Wanapat et al. (2003) investigated the

microorganisms in cattle and swamp buffaloes and observed that swamp buffaloes exhibit a

stronger ability to digest cellulose than cattle due to their greater abundance of bacteria

$\left(1.6 \times 10^{9} / \mathrm{mL}\right)$ compared with that of cattle $\left(1.36 \times 10^{9} / \mathrm{mL}\right)$. In our study, the HS3 group $(\mathrm{C}: \mathrm{F}$

ratio 30:70) exhibited a richer microbial community and an increased in microbial

diversity. Therefore, the inclusion of $30 \%$ concentrate in feed might be a good choice of diet that

can be provided to Tibetan sheep. However, we did not perform digestibility experiments with

all the treatments, which is a limitation of this study. Therefore, whether a rumen environment

with a high bacterial richness and a high bacterial diversity is associated with a higher digestive

capacity of Tibetan sheep remains to be investigated.

\section{Conclusion}

The different dietary C: F ratios affected the growth performance, rumen fermentation and rumen bacterial diversity of Tibetan sheep. Increasing the dietary concentrate feed level from $0 \%$ to $60 \%$ exerted a positive effect on the DMI, BW gain, gain rate and $\mathrm{F}_{\mathrm{CR}}$ of Tibetan sheep during late non-growing and green-up period, and Tibetan sheep fed with $45 \%$ concentrate level for barn feeding can result in a better improvement in animal performance. Moreover, high C:F ratios significantly increased ammonium nitrogen, reduced the A:P molar ratio and changed the composition of the bacterial community. 
413

414

415

416

417

418

419

420

421

422

423

424

425

426

427

428

429

430

431

432

433

434

435

\section{Acknowledgement}

We would like to thank Yinfa Ji for his help in sampling. We also thank Hanzhong Ji, senior livestock engineer from Haibei Prefecture, for providing the experiment site.

\section{Competing Interests}

The authors declare no competing interests.

\section{Funding}

This work was supported by National Key R\&D Plan (2016YFC0501905, 2016YFC0501805), the "Strategic Priority Research Program” of CAS, "Key Technology

Support Program" of Qinghai province (2018-S-2, 2015-SF-A4-2, 2016-NK-148, 2017-SF-A6, 2017-NK-153), the Qinghai innovation platform construction project (2017-ZJ-Y20) and NSFC 31402120.

\section{Data Availability}

The sequencing data for the $16 \mathrm{~S}$ rRNA genes are publicly available in the NCBI (https://www.ncbi.nlm.nih.gov/) Short Read Archive under accession. No. PRJNA477411.

\section{References}

Amato KR, Yeoman CJ, Kent A, Righini N, Carbonero F, Estrada A, Gaskins HR, Stumpf RM, Yildirim S, Torralba M, Gillis M, Wilson BA, Nelson KE, White BA, and Leigh SR. 2013. Habitat degradation impacts black howler monkey (Alouatta pigra) gastrointestinal microbiomes. ISME J 7:1344-1353 DOI 10.1038/ismej.2013.16.

An D, Dong X, and Dong Z. 2005. Prokaryote diversity in the rumen of yak (Bos grunniens) and Jinnan cattle (Bos taurus) estimated by 16S rDNA homology analyses. Anaerobe 11:207-215 DOI 10.1016/j.anaerobe.2005.02.001.

Andrade PVD, and Schmidely P. 2006. Influence of percentage of concentrate in combination 
436

437

438

439

440

441

442

443

444

with rolled canola seeds on performance, rumen fermentation and milk fatty acid composition in dairy goats. Livestock Science 104:77-90 DOI 10.1016/j.livsci.2006.03.010.

Baruah K, Paul V, Ahmed F, Chakravarty P, Deori S, Sarma H, and Saikia A. 2012. Effect of strategic feed supplementation on growth performance and nutrient utilization in yak calves during winter. Indian Journal of Animal Sciences 82:220. DOI 10.1016/j.applanim.2012.01.004.

Briesacher S, May T, Grigsby K, Kerley M, Anthony R, and Paterson J. 1992. Use of DNA probes to monitor nutritional effects on ruminal prokaryotes and Fibrobacter succinogenes S85. Journal of Animal Science 70:289-295. DOI 10.2527/1992.701289x.

\section{Caporaso JG, Kuczynski J, Stombaugh J, Bittinger K, Bushman FD, Costello EK, Fierer} N, Pena AG, Goodrich JK, and Gordon JI. 2010. QIIME allows analysis of highthroughput community sequencing data. Nature methods 7:335. DOI 10.1038/nmeth.f.303. DOI 10.1038/nmeth.f.303.

Ceconi I, Ruiz-Moreno M, DiLorenzo N, DiCostanzo A, and Crawford GI. 2015. Effect of urea inclusion in diets containing corn dried distillers grains on feedlot cattle performance, carcass characteristics, ruminal fermentation, total tract digestibility, and purine derivatives-to-creatinine index. Journal of Animal Science 93:357-369 DOI $10.2527 /$ jas.2014-8214.

Cerrillo MA, Russell JR, and Crump MH. 1999. The effects of hay maturity and forage to concentrate ratio on digestion kinetics in goats. Small Ruminant Research 32:51-60 DOI 10.1016/s0921-4488(98)00153-9.

Chen G, Song S, Wang B, Zhang Z, Peng Z, Guo C, Zhong J, and Wang Y. 2015a. Effects 
459

460

461

462

463

464

465

466

467

468

469

470

471

472

473

474

475

476

477

478

479

480

481

of forage: concentrate ratio on growth performance, ruminal fermentation and blood metabolites in housing-feeding yaks. Asian-Australasian Journal of Animal Sciences 28:1736 DOI 10.5713/ajas.15.0419.

Chen GJ, Song SD, Wang BX, Zhang ZF, Peng ZL, Guo CH, Zhong JC, and Wang Y. 2015b. Effects of Forage:Concentrate Ratio on Growth Performance, Ruminal Fermentation and Blood Metabolites in Housing-feeding Yaks. Asian-Australas J Anim Sci 28:1736-1741 DOI 10.5713/ajas.15.0419.

Chen Y-B, Lan D-L, Tang C, Yang X-N, and Li J. 2015c. Effect of DNA extraction methods on the apparent structure of yak rumen microbial communities as revealed by $16 \mathrm{~s}$ rdna sequencing. Polish Journal of Microbiology 64:29-36.

Dong QM, Zhao XQ, Ma YS, Xu SX, and Li QY. 2006. Live-weight gain, apparent digestibility, and economic benefits of yaks fed different diets during winter on the Tibetan plateau. Livestock Science 101:199-207. DOI 10.1016/j.Lnivprodsc i.2005.11.009.

Dodd D, Mackie RI, and Cann IK. 2011. Xylan degradation, a metabolic property shared by rumen and human colonic Bacteroidetes. Mol Microbiol 79:292-304 DOI 10.1111/j.13652958.2010.07473.x.

Edgar RC, Haas BJ, Clemente JC, Quince C, and Knight R. 2011. UCHIME improves sensitivity and speed of chimera detection. Bioinformatics 27:2194-2200. DOI 10.1093/bioinformatics/btr381.

Feng BF, Zhao XQ, Dong QM, Xu SX, Zhao L, and Cao J. 2013. The Effect of Feed Supplementing and Processing on the Live Weight Gain of Tibetan Sheep During the Cold Season on the Qinghai-Tibetan Plateau. Journal of Animal \& Veterinary Advances 
482

483

484

485

486

487

488

489

490

491

492

493

494

495

496

497

498

499

500

501

502

503

504

12:312-315. DOI 10.3923/javaa.2013.312-315

Haddad SG, and Ata MA. 2009. Growth performance of lambs fed on diets varying in concentrate and wheat straw. Small Ruminant Research 81:96-99. DOI 10.1016/j.smallrumres.2008.11.015.

Haddad SG. 2005. Effect of dietary forage:concentrate ratio on growth performance and carcass characteristics of growing Baladi kids. Small Ruminant Research 57:43-49. DOI 10.1016/j.smallrumres.2004.05.001.

\section{Henderson G, Cox F, Kittelmann S, Miri VH, Zethof M, Noel SJ, Waghorn GC, and} Janssen PH. 2013. Effect of DNA extraction methods and sampling techniques on the apparent structure of cow and sheep rumen microbial communities. PLoS One 8:e74787 DOI 10.1371/journal.pone.0074787.

Henderson G, CoxF, Ganesh S, Jonker, A, Young W, and Janssen PH. 2015 Rumen microbial community composition varies with diet and host, but a core microbiome is found across a wide geographical range. Sci. Rep. 6:14567. DOI 10.1038/srep19175.

Hobson PN, and Stewart CS. 2012. The rumen microbial ecosystem: Springer Science \& Business Media.

Huo W, Zhu W, and Mao S. 2014. Impact of subacute ruminal acidosis on the diversity of liquid and solid-associated bacteria in the rumen of goats. World Journal of Microbiology \& Biotechnology 30:669-680 DOI 10.1007/s11274-013-1489-8.

Jami E, Israel A, Kotser A, and Mizrahi I. 2013. Exploring the bovine rumen bacterial community from birth to adulthood. Isme Journal Multidisciplinary Journal of Microbial Ecology 7:1069. DOI 10.1007/s11274-013-1489-8.

Jiang S, Yang Z, Yang W, Li Z, Zhang C, Liu X, and Wan F. 2015. Diets of differentially 
505

506

507

508

509

510

511

512

513

514

515

516

517

518

519

520

521

522

523

524

525

526

527

processed wheat alter ruminal fermentation parameters and microbial populations in beef cattle. Journal of Animal Science 93:5378-5385. DOI 10.2527/jas.2015-9547.

Jiao J, Huang J, Zhou C, and Tan Z. 2015. Taxonomic Identification of Ruminal Epithelial Bacterial Diversity during Rumen Development in Goats. Appl Environ Microbiol 81:3502-3509. DOI 10.1128/AEM.00203-15.

Lee HJ, Jung JY, Oh YK, Lee SS, Madsen EL, and Jeon CO. 2012. Comparative survey of rumen microbial communities and metabolites across one caprine and three bovine groups, using bar-coded pyrosequencing and ${ }^{1} \mathrm{H}$ nuclear magnetic resonance spectroscopy. Applied \& Environmental Microbiology 78:5983. DOI 10.1128/AEM.00104-12.

Lettat A, Noziere P, Silberberg M, Morgavi DP, Berger C, and Martin C. 2010. Experimental feed induction of ruminal lactic, propionic, or butyric acidosis in sheep. J Anim Sci 88:3041-3046. DOI 10.2527/jas.2010-2926.

Li M, Penner GB, Hernandez-Sanabria E, Oba M, and Guan LL. 2009. Effects of sampling location and time, and host animal on assessment of bacterial diversity and fermentation parameters in the bovine rumen. $J$ Appl Microbiol 107:1924-1934. DOI 10.1111/j.13652672.2009.04376.x.

Li LQ, Ma YS, Li SX, Wang XL, Wang YL, Jing ML, Li SY, Nian Y and Han HL.2017. Effects of rest-grazing in the regreen-up period on moderately degreaded steppification meadow of Qilian Mountain. Pratacultural Science 10:2016-2022 DOI 10.11829/j.issn.1001-0629.2017-0200.

Li W. 2012. The Effect and Influence Factors of Rumen Volatile Fatty Acid. Chinese Journal of Animal Science 48: 63-66. 
528 Lin B, Henderson G, Zou C, Cox F, Liang X, Janssen PH, and Attwood GT. 2015.

529 Characterization of the rumen microbial community composition of buffalo breeds

530

531

532

533

534

535

536

537

538

539

540

541

542

543

544

545

546

547

548

549

550

Ma HY. 2008. Biomass measurement and Tibetan sheep barn supplementing experiment during spring rest-garzing period in alphine pasture aera. Prataculture \&Anim Husbandry 6:3435.

Moorby JM, Dewhurst RJ, Evans RT, Danelo'n $\dagger$ JL. 2006. Effects of Dairy Cow Diet Forage Proportion on Duodenal Nutrient Supply and Urinary Purine Derivative Excretion. J. Dairy Sci. 89: 3552-3562. DOI 10.1016/j.livsci.2013.11.013.

Minuti A, Ahmed S, Trevisi E, Piccioli-Cappelli F, Bertoni G, Jahan N, and Bani P. 2014. Experimental acute rumen acidosis in sheep: consequences on clinical, rumen, and gastrointestinal permeability conditions and blood chemistry. J Anim Sci 92:3966-3977. DOI 10.2527/jas.2014-7594.

Nocek, J. E. 1997. Bovine acidosis: Implications on laminitis. J. Dairy Sci. 80:1005-1028 DOI 
551

552

553

554

555

556

557

558

559

560

561

562

563

564

565

566

567

568

569

570

571

572

573

10.3168/jds.S0022-0302(97)76026-0

\section{Petri RM, Schwaiger T, Penner GB, Beauchemin KA, Forster RJ, McKinnon JJ, and} McAllister TA. 2013. Characterization of the core rumen microbiome in cattle during transition from forage to concentrate as well as during and after an acidotic challenge. PLoS One 8:e83424 DOI 10.1371/journal.pone.0083424.

Pitta D, Kumar S, Veiccharelli B, Parmar N, Reddy B, and Joshi C. 2014. Bacterial diversity associated with feeding dry forage at different dietary concentrations in the rumen contents of Mehshana buffalo (Bubalus bubalis) using 16S pyrotags. Anaerobe 25:31-41 DOI 10.1016/j.anaerobe.2013.11.008.

Polyorach S, Wanapat M, and Cherdthong A. 2014. Influence of Yeast Fermented Cassava Chip Protein (YEFECAP) and Roughage to Concentrate Ratio on Ruminal Fermentation and Microorganisms Using In vitro Gas Production Technique. Asian-Australas J Anim Sci 27:36-45 DOI 10.5713/ajas.2013.13298.

Porebski S, Bailey LG, and Baum BR. 1997. Modification of a CTAB DNA extraction protocol for plants containing high polysaccharide and polyphenol components. Plant Molecular Biology Reporter 15:8-15 DOI 10.1007/bf02772108.

Ramos-Morales E, Arco-Pérez A, Martín-García AI, Yáñez-Ruiz DR, Frutos P, and Hervás G. 2014. Use of stomach tubing as an alternative to rumen cannulation to study ruminal fermentation and microbiota in sheep and goats. Animal Feed Science and Technology 198:57-66 DOI 10.1016/j.anifeedsci.2014.09.016.

Reddy. KJ, and Reddy. M. 1985. Effect of feeding complete feeds on various nitrogen fractions and total VFA concentrations in the rumen fluid of sheep. Indian Journal of Animal Sciences. DOI 10.1051/gse:19850410. 
574

575

576

577

578

579

580

581

582

583

584

585

586

587

588

589

590

591

592

593

594

595

596

Rhine ED, Mulvaney RL, Pratt EJ, and Sims GK. 1998. Improving the Berthelot Reaction for Determining Ammonium in Soil Extracts and Water. Soil Science Society of America Journal 62:473-480. DOI $\quad 10.2136 /$ sssaj1998.03615995006200020026x.

Sasaki M. 1994. Yak: Hardy multi-purpose animal of Asian highland. Asian Livestock (FAO).

Soest PJV, Robertson JB, and Lewis BA. 1991. Methods for Dietary Fiber, Neutral Detergent Fiber, and Nonstarch Polysaccharides in Relation to Animal Nutrition. Journal of Dairy Science 74:3583-3597. DOI 10.3168/jds.S0022-0302(91)78551-2.

Stevenson DM, and Weimer PJ. 2007. Dominance of Prevotella and low abundance of classical ruminal bacterial species in the bovine rumen revealed by relative quantification real-time PCR. Appl Microbiol Biotechnol 75:165-174 DOI 10.1007/s00253-006-0802-y.

Strobel HJ. 1992. Vitamin B12-dependent propionate production by the ruminal bacterium Prevotella ruminicola 23. Appl Environ Microbiol 58:2331-2333.

Wanapat M, Nontaso N, Yuangklang C, Wora-anu S, Ngarmsang A, Wachirapakorn C, and Rowlinson P. 2003. Comparative study between swamp buffalo and native cattle in feed digestibility and potential transfer of buffalo rumen digesta into cattle. Asian Australasian Journal of Animal Sciences 16:504-510 DOI 10.5713/ajas.2003.504.

Wang QL, Hua LM, Wang GZ, and Liu L. 2015. Effect of defered grazing on grassland community characteristics and productivity in a lphine meadow.Acta Agrectir Sinica 23:1068-1072.

Wang W, Li C, Li F, Wang X, Zhang X, Liu T, Nian F, Yue X, Li F, Pan X, La Y, Mo F, Wang F, and Li B. 2016. Effects of early feeding on the host rumen transcriptome and bacterial diversity in lambs. Sci Rep 6:32479 DOI 10.1038/srep32479. 
597 Weng XX 2013. The study on rumen fermentation, volatile fatty acid absorption chacrcteristics

598

599

600

601

602

603

604

605

606

607

608

609

610

611

612

613

614

615

616

617

618

619

and genen expression in dairly cows receiving different types od diets [D] Lanzhou:

Gansu Agricultural University

Weimer PJ, Stevenson DM, Mertens DR, and Thomas EE. 2008. Effect of monensin feeding and withdrawal on populations of individual bacterial species in the rumen of lactating dairy cows fed high-starch rations. Appl Microbiol Biotechnol 80:135-145. DOI $10.1007 / \mathrm{s} 00253-008-1528-9$.

Wiener G, Han JL, Long RJ, Wiener G, Han JL, and Long RJ. 2003. Origins, domestication and distribution of yak. Yak.

Xie J, Yan SM, Li J, Zhao YG, Wu TM, Shi Y, and Guo XY. 2014. Effect of supplementary feeding of grazing Hulunbuir lacting ewes on lamb growth performance and ewe weight during the spring. Feed Industry 35: 43-46.

Xue.B, Zhao. XQ, Zhang YS. 2005. Seasonal changes in weight and body composition of yak grazing on alpinemeadow grassland in the Qinghai-Tibetan plateau of China. J. Anim. Sci. 83:1908-1913. DOI 10.2527/2005.8381908x.

Xue D, Chen H, Chen F, He Y, Zhao C, Zhu D, Zeng L, and Li W. 2016. Analysis of the rumen bacteria and methanogenic archaea of yak (Bos grunniens) steers grazing on the Qinghai-Tibetan Plateau. Livestock Science 188:61-71 DOI 10.1016/j.livsci.2016.04.009.

Yang WZ, Beauchemin. K A, Rode LM. 2001. Effects of Grain Processing, Forage to Concentrate Ratio, and Forage Particle Size on Rumen $\mathrm{pH}$ and Digestion by Dairy Cows. $J$. Dairy Sci. 84:2203-2216. DOI 10.3168/jds.S0022-0302(01)74667-X.

Zhang T, Zhuang S, Dong WC, Chang GJ, Yan R, Wang T. 2013. Effects of different dietary concentrate to forage ratios on rumen fluid $\mathrm{pH}$ and VFA levels and blood VFA levels 
620 in dairy goats. Animal Husbandry and Veterinary Medicine 4: 5-10.

621

622

623

624

625

626 
Figure 1

Figure 1 The rarefaction analysis anomg the 20 different samples.

The group HS1 samples included sheep HS1.1, HS1.2, HS1.3 and HS1.4. The treatment HS2 samples included sheep HS2.1, HS 2.2, HS2.3 and HS4. The treatment HS3 samples included sheep HS3.1, HS3.2 HS3.3 and HS3.4. The treatment HS4 samples included HS4.1, HS4.2, HS4.3 and H4.4. The treatment HS5 samples included HS5.1, HS5.2, HS5.3 and H5.4. The treatment $\mathrm{HS} 1=$ concentrate to forage ratio $0: 100, \mathrm{HS} 2=$ concentrate to forage ratio 15:85, $\mathrm{HS} 3=$ concentrate to forage ratio $30: 70, \mathrm{HS} 4=$ concentrate to forage ratio $45: 55$, HS5 =concentrate to forage ratio 60:40. 


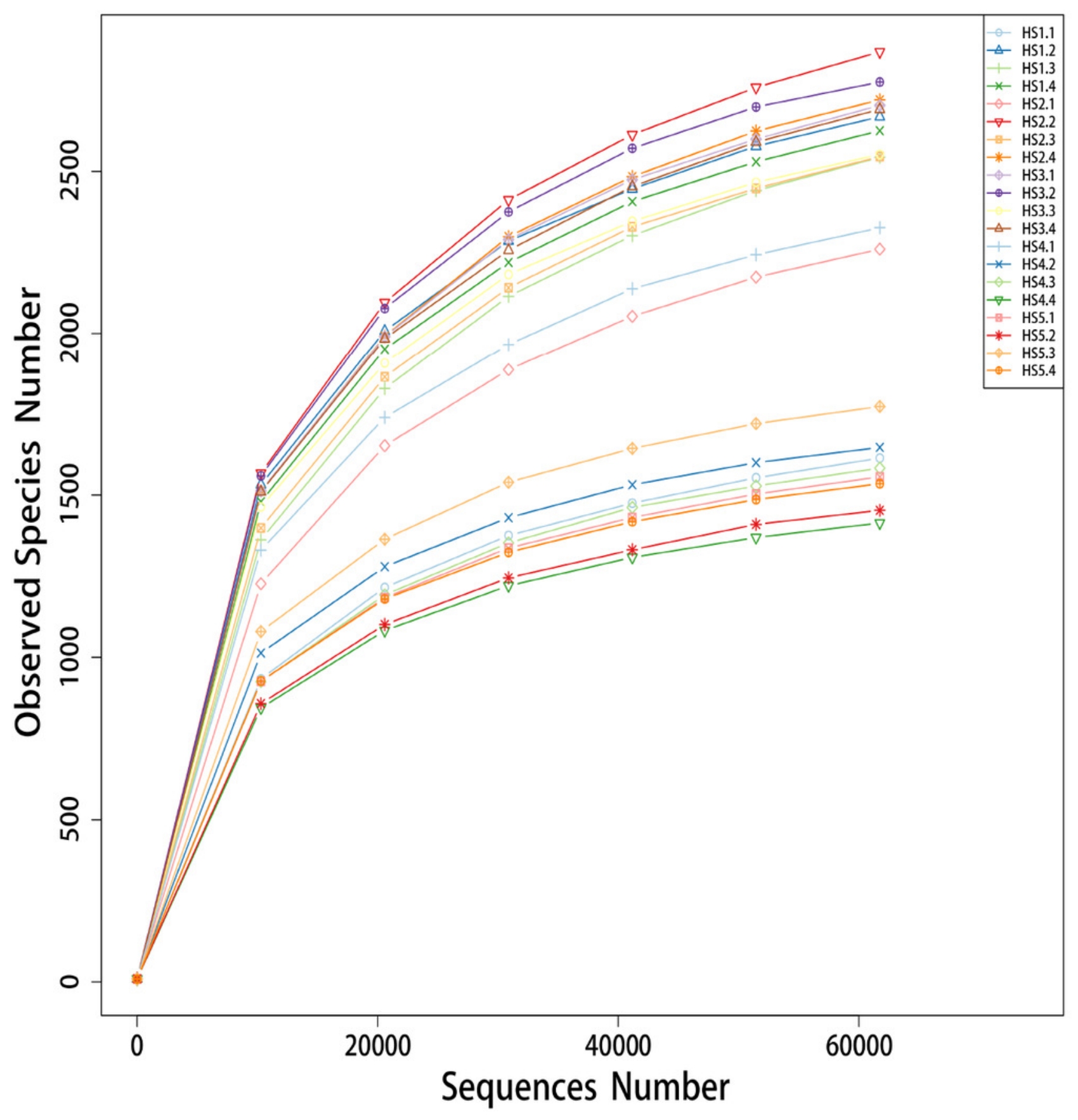




\section{Figure 2}

Dominant bacterial phylum in individual samples and the shared genera across the ruminal samples.

(A) The top 10 shared bacterial taxonomic composition across ruminal samples at the phylum level. (B) The top 10 shared bacterial toxonomic composition across ruminal samples.

Percentage is shown on the $\mathrm{X}$-axis. The box represent the interquartile range between the first and the third quartiles, and the symbol"-- " represent the max value, " $x$ " represent the variation range from $1 \%$ to $99 \%$ and " $\square$ "represent the mean value. The treatment $\mathrm{HS} 1=$ concentrate to forage ratio $0: 100, \mathrm{HS} 2=$ concentrate to forage ratio $15: 85, \mathrm{HS} 3=$ concentrate to forage ratio $30: 70, \mathrm{HS} 4=$ concentrate to forage ratio $45: 55, \mathrm{HS} 5=$ concentrate to forage ratio $60: 40$.

(A)

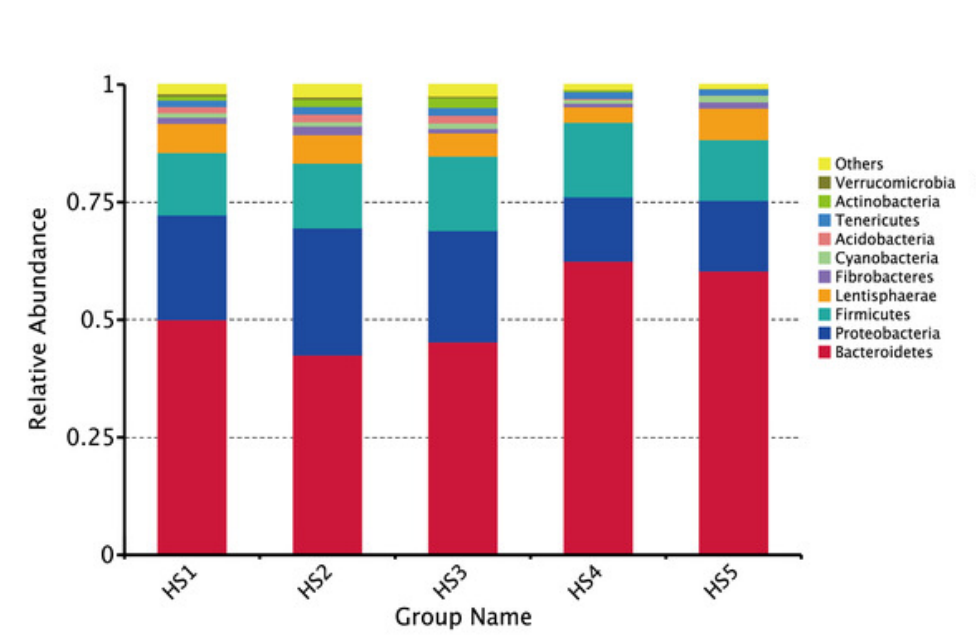

(B)

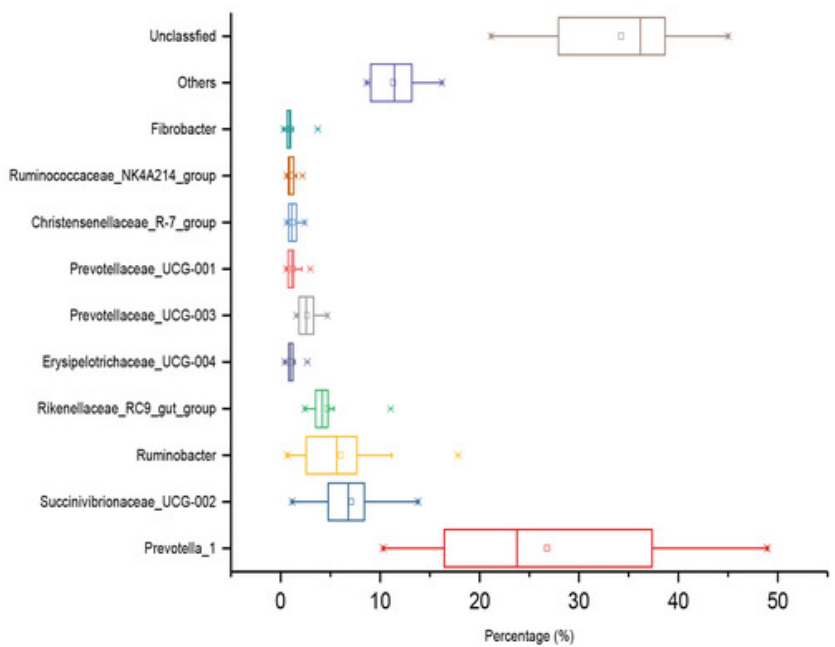


Figure 3

The differences in bacteria community diversity and richness indexes among different feeding treatment.

(A) The Shannon-Wiener diversity among each treatment. (B)The Chaol richness estimator among each treatment. (C) The observed species in each treatment. (D) The good coverage in samples among each treatment. The treatment $\mathrm{HS} 1=$ concentrate to forage ratio 0:100, HS2 = concentrate to forage ratio $15: 85, \mathrm{HS} 3=$ concentrate to forage ratio $30: 70, \mathrm{HS} 4=$ concentrate to forage ratio $45: 55, \mathrm{HS} 5=$ concentrate to forage ratio $60: 40$.

(A)

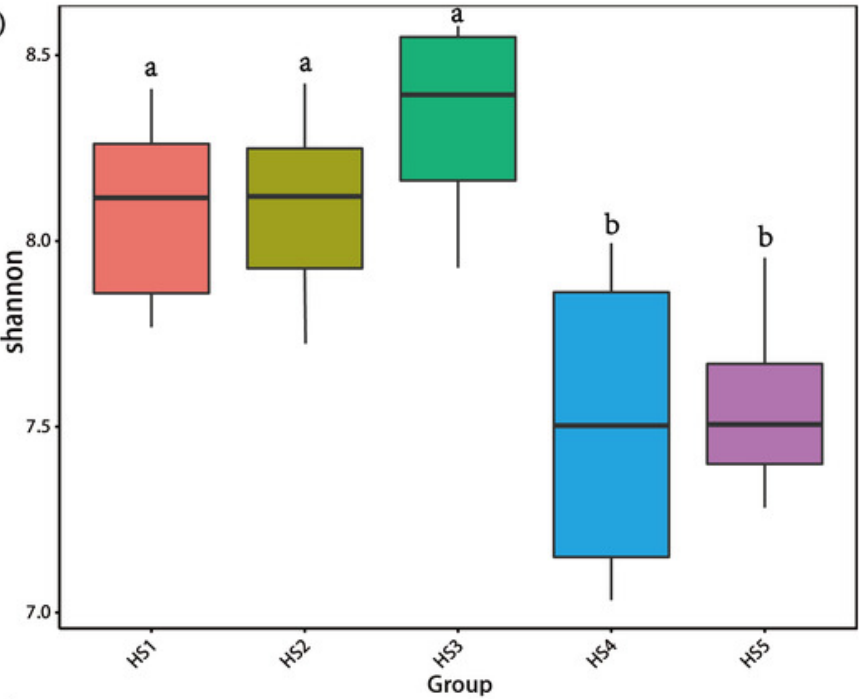

(C)

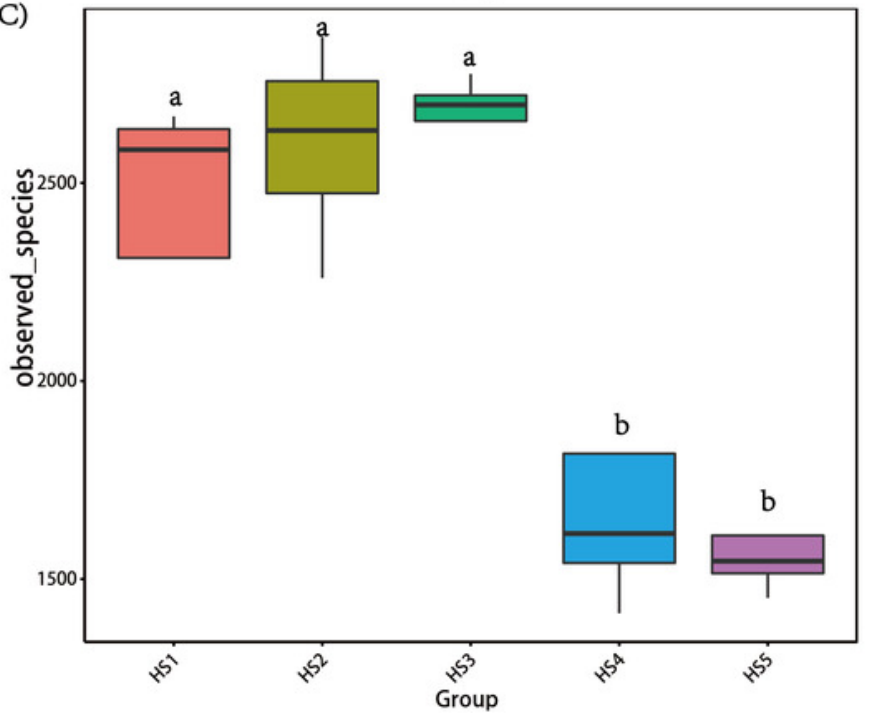

(B)

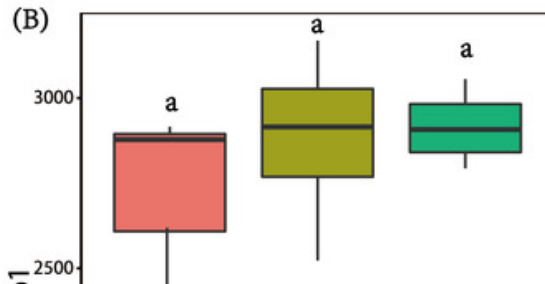

온

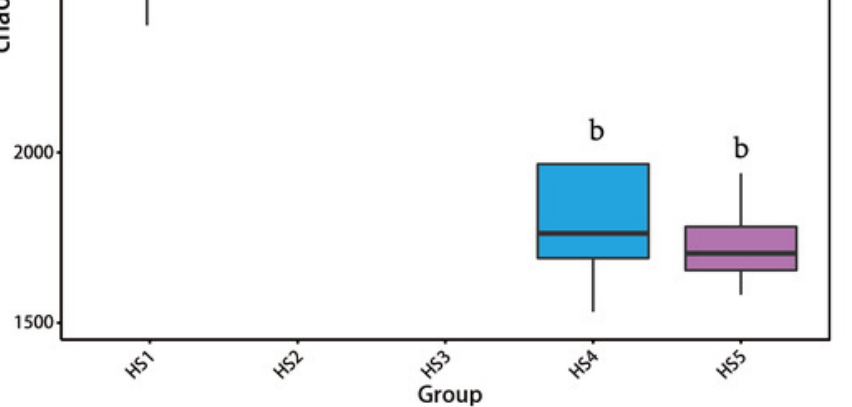

(D)

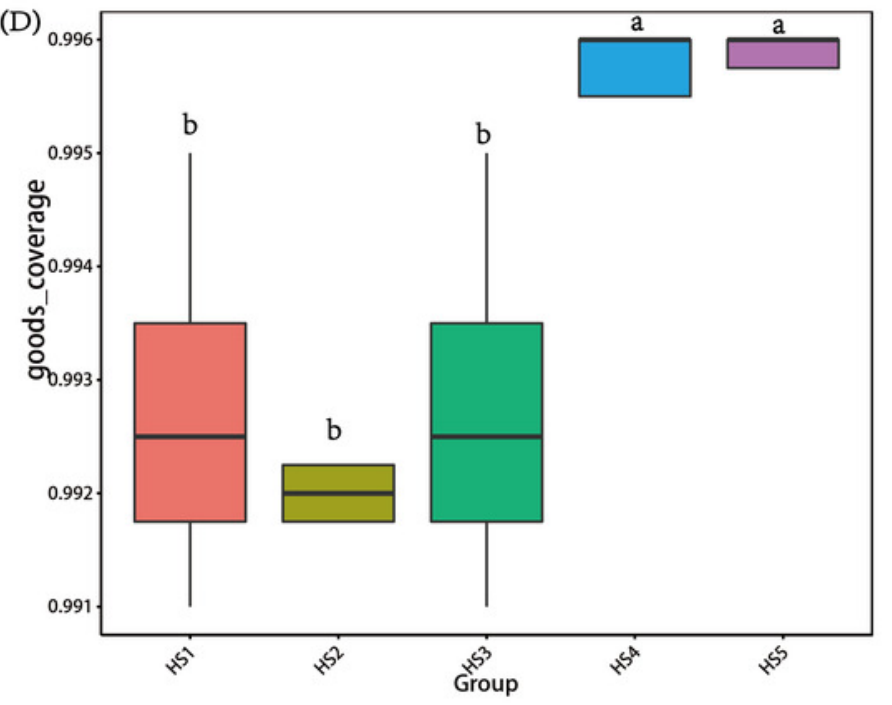


Figure 4

The principal coordinate analysis (PCOA) using weighted UniFrac metrics.

The treatment $\mathrm{HS} 1=$ concentrate to forage ratio $0: 100, \mathrm{HS} 2=$ concentrate to forage ratio 15:85, HS3 = concentrate to forage ratio $30: 70, \mathrm{HS} 4=$ concentrate to forage ratio $45: 55$, $\mathrm{HS5}=$ concentrate to forage ratio 60:40.

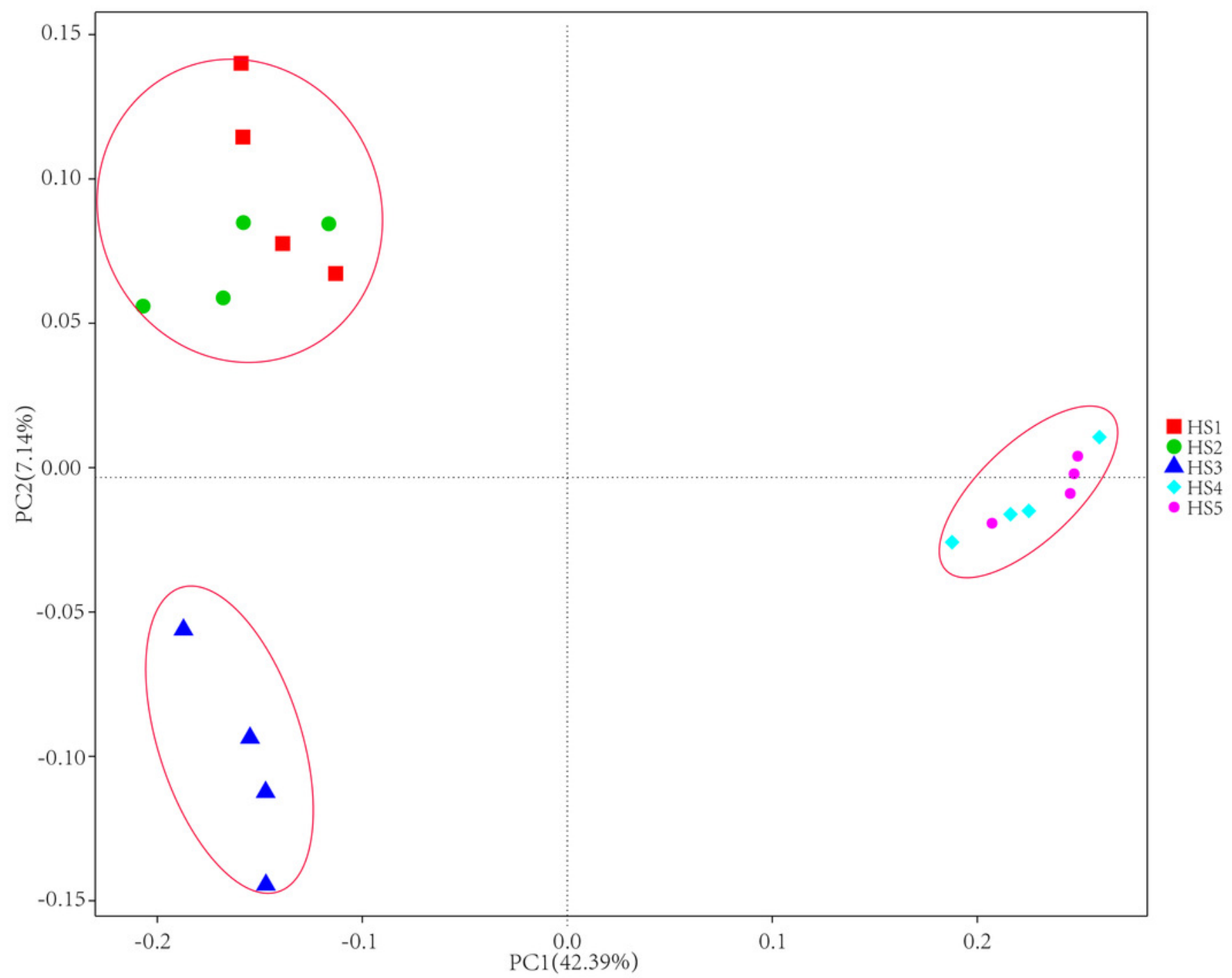




\section{Figure 5}

The heat map of the correlations between bacterial diversity and growth performance of Tibetan sheep.

$D M I=$ dry matter intake; $A D G=$ average daily body weight gain; $F C R=$ feed conversion ratio; BW again = body weight gain. The treatment $\mathrm{HS} 1=$ concentrate to forage ratio $0: 100, \mathrm{HS} 2=$ concentrate to forage ratio $15: 85, \mathrm{HS} 3=$ concentrate to forage ratio $30: 70, \mathrm{HS} 4=$ concentrate to forage ratio $45: 55, \mathrm{HS} 5=$ concentrate to forage ratio $60: 40$. * significant at $\mathrm{P}<0.05$.

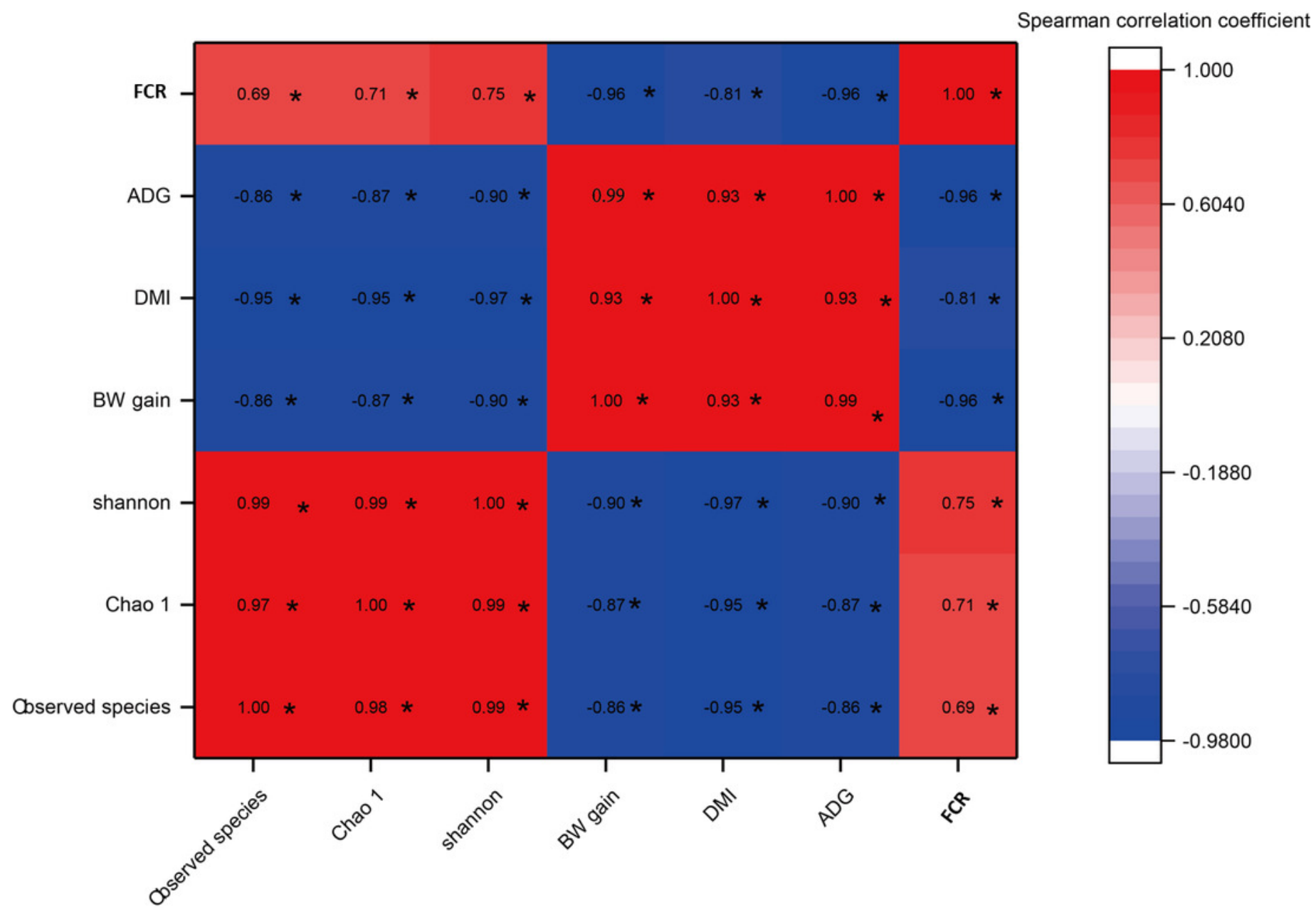


Figure 6

The heat map of the correlations between bacterial diversity and growth performance of Tibetan sheep.

$\mathrm{DMI}=$ dry matter intake; $\mathrm{ADG}=$ average daily body weight gain; $\mathrm{FCR}=$ feed conversion ratio; BW again= body weight gain. The treatment $\mathrm{HS} 1=$ concentrate to forage ratio $0: 100, \mathrm{HS} 2=$ concentrate to forage ratio $15: 85, \mathrm{HS} 3=$ concentrate to forage ratio $30: 70, \mathrm{HS} 4=$ concentrate to forage ratio $45: 55, \mathrm{HS} 5=$ concentrate to forage ratio $60: 40$. * Significant at $\mathrm{P}<0.05$.

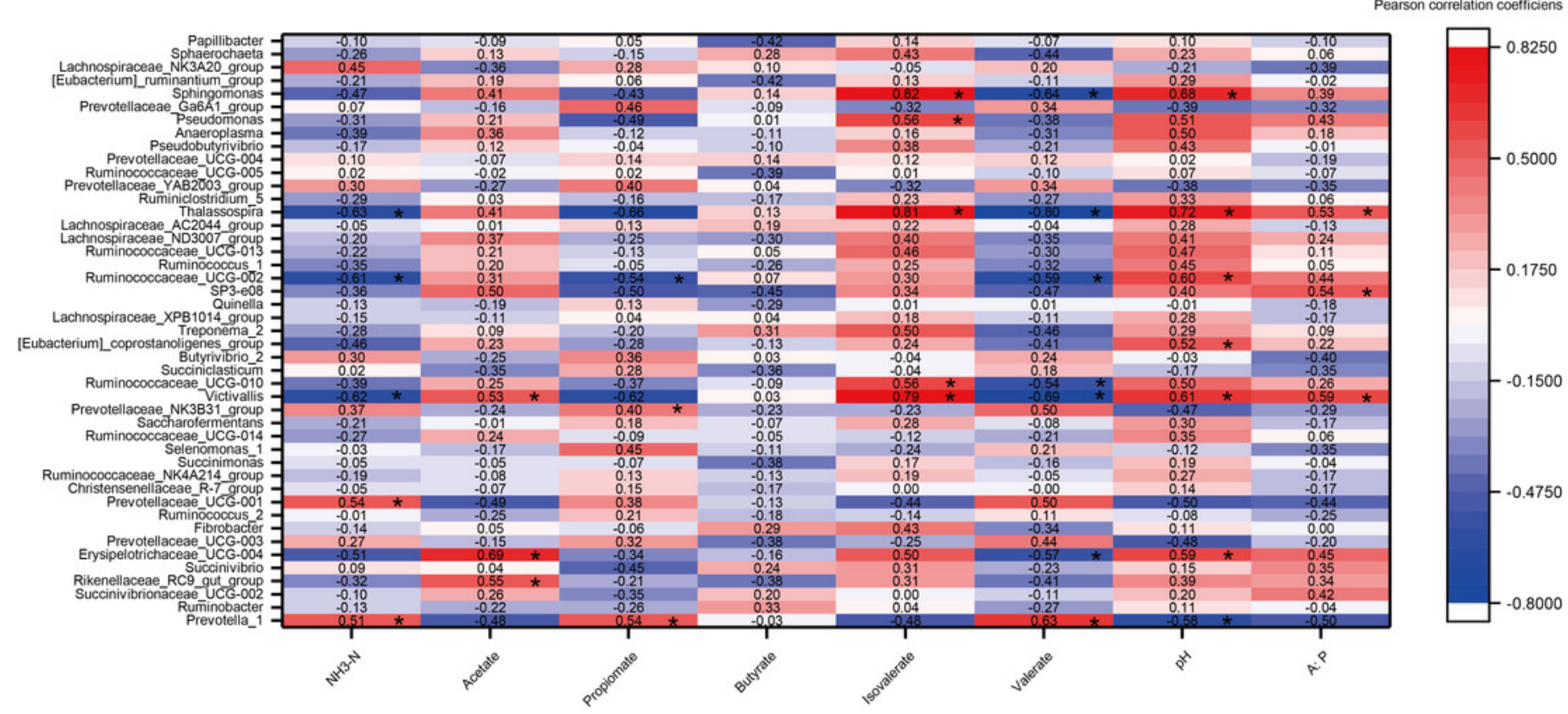




\section{Table $\mathbf{1}$ (on next page)}

The nutritional composition of the whole diets among different treatments (\% DM basis).

${ }^{a}$ The tratments HS1, HS2, HS3, HS4 and HS5 refer to the C:F ratios of $0: 100,15: 85,30: 70$, 45:55 and $60: 40$, respectively. ${ }^{\mathrm{b}} \mathrm{DM}=$ dry matter; $\mathrm{CP}=$ crude protein; $\mathrm{EE}=$ ether extract; $\mathrm{ADF}=$ acid detergent fibre; NDF= neutral detergent fibre. ${ }^{\mathrm{C}}$ Manufactured by Menyuan Yongxing Ecological Agricultural Development Co., Ltd. Contained corn (48\%), wheat (30\%), soybean meal (7\%), colza cake (6\%)cottonseed meal (5\%), , salt (1\%), pre-mix (1\%),CaHPO4 $(1 \%)$ and $\mathrm{CaCO}_{3}(1 \%)$. 


\begin{tabular}{|c|c|c|c|c|c|}
\hline \multirow{2}{*}{ Items } & \multicolumn{5}{|c|}{ Groups $^{\text {a }}$} \\
\hline & HS1 & HS2 & HS3 & HS4 & HS5 \\
\hline \multicolumn{6}{|l|}{ Ingredient (\%) } \\
\hline Concentrate feeds ${ }^{c}$ & 0 & 15 & 30 & 45 & 60 \\
\hline Oats hay & 100 & 85 & 70 & 55 & 40 \\
\hline \multicolumn{6}{|l|}{ Nutrient content } \\
\hline $\mathrm{DM}^{\mathrm{b}}$ & 93.42 & 92.70 & 91.82 & 91.23 & 90.35 \\
\hline $\mathrm{CP}$ & 6.31 & 7.69 & 9.37 & 10.38 & 11.94 \\
\hline Starch (mg/g) & 25.58 & 26.95 & 32.55 & 33.72 & 39.37 \\
\hline $\mathrm{EE}$ & 2.13 & 2.21 & 2.36 & 2.37 & 2.49 \\
\hline $\mathrm{ADF}$ & 34.1 & 30.68 & 27.33 & 23.79 & 19.64 \\
\hline NDF & 57.64 & 52.04 & 44.85 & 39.05 & 33.12 \\
\hline Calcium & 0.35 & 0.40 & 0.48 & 0.55 & 0.61 \\
\hline Magnesium & 0.24 & 0.27 & 0.32 & 0.35 & 0.42 \\
\hline Phosphorus & 0.22 & 0.27 & 0.33 & 0.38 & 0.45 \\
\hline
\end{tabular}




\section{Table 2 (on next page)}

The effects of different dietary C: $F$ ratios on the growth performance of Tibetan sheep.

${ }^{a}$ The treatments HS1, HS2, HS3, HS4 and HS5 refer to concentrate-to-forage ratios of $0: 100,15: 85,30: 70,45: 55$ and 60:40. $\mathrm{DMI}=$ dry matter intake; DM consume $=\mathrm{DMI} \times \mathrm{t}$, $\mathrm{t}$ is experimental time(d), BW=body weight; $A D G=$ average daily $B W$ gain . $F C R=$ feed conversion ratio. Values in the same row with different superscripts are significantly different $(\mathrm{P}<0.05)$. 


\begin{tabular}{|c|c|c|c|c|c|c|}
\hline \multirow{2}{*}{ Items } & \multicolumn{5}{|c|}{ Groups ${ }^{\mathrm{a}}$} & \multirow{2}{*}{ p-value } \\
\hline & HS1 & HS2 & HS3 & HS4 & HS5 & \\
\hline Initial BW (kg) & $21.31 \pm 0.92$ & $22.13 \pm 3.06$ & $21.25 \pm 1.69$ & $19.88 \pm 1.1 .81$ & $22.19 \pm 2.34$ & 0.196 \\
\hline Final BW(kg) & $23.81 \pm 1.25^{\mathrm{d}}$ & $26.44 \pm 3.07^{\mathrm{cd}}$ & $28.38 \pm 2.23^{\mathrm{bc}}$ & $29.75 \pm 2.62^{b}$ & $32.94 \pm 3.49^{\mathrm{a}}$ & $<0.01$ \\
\hline BW gain $(\mathrm{kg})$ & $2.50 \pm 0.76^{\mathrm{d}}$ & $4.31 \pm 1.92^{\mathrm{c}}$ & $7.13 \pm 1.71^{\mathrm{b}}$ & $9.88 \pm 1.43^{\mathrm{a}}$ & $10.75 \pm 1.79^{\mathrm{a}}$ & $<0.01$ \\
\hline Gain rate $(\%)$ & $11.73 \pm 3.50^{\mathrm{d}}$ & $19.93 \pm 6.54^{c}$ & $33.78 \pm 8.63^{b}$ & $49.98 \pm 7.13 \mathrm{a}$ & $48.59 \pm 7.56^{\mathrm{a}}$ & $<0.01$ \\
\hline $\operatorname{ADG}(g / d)$ & $31.25 \pm 9.45^{\mathrm{d}}$ & $53.91 \pm 12.91^{\mathrm{c}}$ & $89.06 \pm 21.33^{b}$ & $123.44 \pm 17.91^{\mathrm{a}}$ & $134.38 \pm 22.41^{\mathrm{a}}$ & $<0.01$ \\
\hline DMI (g/d) & $670.30 \pm 45.26^{c}$ & $719.16 \pm 120.09^{b c}$ & $741.21 \pm 71.22^{\mathrm{abc}}$ & $807.68 \pm 32.29^{a b}$ & $851.93 \pm 98.86^{\mathrm{a}}$ & $<0.01$ \\
\hline DM consume (kg) & $53.62 \pm 3.62^{c}$ & $57.53 \pm 8.98^{\mathrm{bc}}$ & $59.30 \pm 5.70^{\mathrm{bc}}$ & $64.61 \pm 4.98^{\mathrm{ab}}$ & $68.15 \pm 7.91^{\mathrm{a}}$ & $<0.01$ \\
\hline FCR & $23.86 \pm 9.75^{\mathrm{a}}$ & $13.94 \pm 3.38^{b}$ & $8.92 \pm 3.06^{\mathrm{c}}$ & $6.67 \pm 1.15^{\mathrm{c}}$ & $6.44 \pm 1.00^{\mathrm{c}}$ & $<0.01$ \\
\hline
\end{tabular}




\section{Table 3 (on next page)}

The effects of different dietary $\mathrm{C}: \mathrm{F}$ ratios on the rumen fermentation parameters of Tibetan sheep.

${ }^{a}$ The Treatments HS1, HS2, HS3, HS4 and HS5 refer to concentrate to forage ratios of 0:100,

15:85, 30:70, 45:55 and 60:40, respectively. ${ }^{b}$ Values in the same row with different superscripts are significantly different $(\mathrm{P}<0.05)$. 


\begin{tabular}{|c|c|c|c|c|c|c|}
\hline \multirow{2}{*}{ Parameters } & \multicolumn{5}{|c|}{ Groups $^{a}$} & \multirow{2}{*}{$\mathrm{P}^{\mathrm{b}}$} \\
\hline & HS1 & HS2 & HS3 & HS4 & HS5 & \\
\hline \multirow[t]{2}{*}{ Ammonia nitrogen $(\mathrm{mg} / \mathrm{L})$} & $46.20 \pm 12.37^{c}$ & $46.20 \pm 12.3$ & $64.00 \pm 3.88^{\mathrm{b}}$ & $67.10 \pm 8.21^{\mathrm{b}}$ & $107.06 \pm 15.0$ & $<0.05$ \\
\hline & & $7^{\mathrm{c}}$ & & & $7^{\mathrm{a}}$ & \\
\hline Acetate $(\%)$ & $77.82^{\mathrm{a}}$ & $71.70^{\mathrm{b}}$ & $64.10^{\mathrm{b}}$ & $60.14 \pm 8.55^{\mathrm{b}}$ & $64.55 \pm 2.15^{\mathrm{b}}$ & 0.32 \\
\hline Propionate (\%) & $12.60 \pm 0.71^{b}$ & $16.02 \pm 0.18^{b}$ & $22.79 \pm 1.13^{\mathrm{a}}$ & $26.81 \pm 3.60^{\mathrm{a}}$ & $29.38 \pm 0.95^{\mathrm{a}}$ & $<0.05$ \\
\hline Butyrate $(\%)$ & $8.25 \pm 0.38$ & $10.66 \pm 1.73$ & $11.30 \pm 0.40$ & $11.51 \pm 2.20$ & $12.02 \pm 0.40$ & 0.23 \\
\hline Isovalerate $(\%)$ & $0.79 \pm 0.10^{\mathrm{a}}$ & $0.92 \pm 0.07^{\mathrm{a}}$ & $0.83 \pm 0.02^{\mathrm{a}}$ & $0.58 \pm 0.03^{b}$ & $0.72 \pm 0.09^{b}$ & 0.23 \\
\hline Valerate $(\%)$ & $0.52 \pm 0.02^{b}$ & $0.70 \pm 0.04^{\mathrm{b}}$ & $0.98 \pm 0.03^{\mathrm{b}}$ & $1.11 \pm 0.04^{\mathrm{a}}$ & $1.50 \pm 0.12^{\mathrm{a}}$ & $<0.05$ \\
\hline Total volatile fatty acids (mmol/L) & $74.94 \pm 10.76$ & $66.12 \pm 2.95$ & $65.21 \pm 1.00$ & $67.44 \pm 1.56$ & $61.24 \pm 7.67$ & 0.11 \\
\hline Acetate to propionate ratio $(\mathrm{A}: \mathrm{P})$ & $6.38 \pm 1.55^{\mathrm{a}}$ & $4.47 \pm 0.16^{\mathrm{a}}$ & $2.85 \pm 0.24^{b}$ & $2.24 \pm 0.39^{b}$ & $2.19 \pm 0.69^{b}$ & $<0.05$ \\
\hline $\mathrm{pH}$ & $6.86 \pm 0.01$ & $6.83 \pm 0.03$ & $6.83 \pm 0.04$ & $6.63 \pm 0.06$ & $6.42 \pm 0.10$ & 0.41 \\
\hline
\end{tabular}

1 